\title{
Effects of awake caudal anesthesia on mean arterial blood pressure in very low birthweight infants
}

\author{
Frank Fideler $^{1^{*}} \mathbb{D}$, Michael Walker ${ }^{2}$ and Christian Grasshoff ${ }^{1}$
}

\begin{abstract}
Background: Intraoperative blood pressure is a relevant variable for postoperative outcome in infants undergoing surgical procedures. It is therefore important to know whether the type of anesthesia has an impact on intraoperative blood pressure management in very low birth weight infants. Here, we retrospectively analyzed intraoperative blood pressure in very low birthweight infants receiving either awake caudal anesthesia without sedation, or caudal block in combination with general anesthesia, both for open inguinal hernia repair.
\end{abstract}

Methods: Ethical approval was provided by the University of Tuebingen Ethical Committee on 05/29/2018 with the project number 403/2018BO2. Patient records of infants admitted by the neonatologist (median age at birth $31.1 \pm$ 3.5 weeks, median weight at birth $1240 \pm 521 \mathrm{~g}$ ) which were scheduled for inguinal hernia repair were retrospectively evaluated for the course of mean arterial blood pressure and perioperative interventions to stabilize blood pressure. A total of 42 patients were included, 16 patients ( 11 boys, 5 girls) received awake caudal anesthesia, 26 patients (22 boys, 4 girls) a combination of general anesthesia and caudal block.

Results: Approximately 3\% of the measured mean arterial blood pressure values in the caudal anesthesia group were below a critical margin of $35 \mathrm{mmHg}$, in contrast to $47 \%$ in the combined anesthesia group $(p<0.001)$. Patients in the latter group showed a significantly larger drop of mean arterial blood pressure below $35 \mathrm{mmHg}$ $(4.7 \pm 2.7 \mathrm{mmHg}$ vs. $1.9 \pm 1.6 \mathrm{mmHg} ; p<0.005)$ and a significantly longer time of mean arterial blood pressure below $35 \mathrm{mmHg}(25.6 \pm 26.0 \mathrm{~min}$ vs. $0.9 \pm 2.3 \mathrm{~min} ; p<0.001)$, although they received more volume and vasopressor boluses for stabilization $(27 \pm 14.8 \mathrm{ml}$ vs. $10 \pm 4.1 \mathrm{ml} ; p<0.01$ and $0.15 \pm 0.06 \mathrm{ml} \mathrm{vs.} 0 \mathrm{ml}$ of cafedrine/theoadrenaline; $p<0.001$.

Conclusions: The study indicates that the use of caudal block as stand alone procedure for inguinal hernia repair in very low birthweight infants might be advantageous in preventing critical blood pressure drops compared to a combination of caudal block with general anesthesia.

\footnotetext{
* Correspondence: frank.fideler@med.uni-tuebingen.de

1 Departmnt of Anesthesiology and Intensive Care Medicine, University Hospital Tuebingen, Tübingen, Germany

Full list of author information is available at the end of the article
}

(C) The Author(s). 2020 Open Access This article is licensed under a Creative Commons Attribution 4.0 International License, which permits use, sharing, adaptation, distribution and reproduction in any medium or format, as long as you give appropriate credit to the original author(s) and the source, provide a link to the Creative Commons licence, and indicate if changes were made. The images or other third party material in this article are included in the article's Creative Commons licence, unless indicated otherwise in a credit line to the material. If material is not included in the article's Creative Commons licence and your intended use is not permitted by statutory regulation or exceeds the permitted use, you will need to obtain permission directly from the copyright holder. To view a copy of this licence, visit http://creativecommons.org/licenses/by/4.0/ The Creative Commons Public Domain Dedication waiver (http://creativecommons.org/publicdomain/zero/1.0/) applies to the data made available in this article, unless otherwise stated in a credit line to the data. 


\section{Background}

The outcome relevance of adequate blood pressure in pediatric surgery has been lately emphasized by several authors [1, 2]. For example, McCann et al. have reported a case series with pediatric patients suffering from infantile postoperative encephalopathy after the occurrence of intraoperative hypotension [3]. This raises the question whether the type of anesthesia has an impact on the need for active intraoperative blood pressure management. To keep blood pressure stable Marhofer et al. promoted the use of caudal and epidural anesthesia under sedation as one possibility to minimize the use of general anesthetic drugs [4]. The authors argued that by the use of regional techniques an avoidance of opioids during the perioperative period might help to reduce cardiorespiratory depression and improve gut function. However, to date there is little evidence supporting the concept that cardiocirculatory parameters in neonates are less impaired during caudal anesthesia compared with general anesthesia. So far, Ing et al. have demonstrated that spinal anesthesia performed in healthy infants undergoing pyloromyotomy results in reduced intraoperative blood pressure changes from baseline compared to general anesthesia [5]. Regarding caudal anesthesia, we already know from previous studies that arterial blood pressure is not altered by caudal anesthesia in children receiving general anesthesia [6], a finding that was supported by a prospective study in neonates by Deng et al. [7].

Thus, to determine whether the use of caudal block as a stand alone method may be advantageous in preventing critical blood pressure drops in the care of very low birthweight infants, we performed a retrospective analysis comparing patients with either awake caudal anesthesia without sedation (CA), or with a caudal block in combination with general anesthesia $(G A+C A)$.

\section{Methods}

Ethical approval for this study was provided by the University of Tuebingen Ethical Committee on 05/29/2018 with the project number 403/2018BO2 (Chairperson Prof D. Luft). Anesthesia in both groups was performed by two senior anesthetists with more than 5 years of experience in the care of very low birthweight infants. Both anesthesiologists provided anesthetics of both types. The decision regarding the technique used was made up to their clinical preference.

\section{Patients' characteristics}

Patient records of infants admitted by the neonatologist which were scheduled for inguinal hernia repair between $01 / 01 / 2012$ and $05 / 22 / 2014$ were retrospectively evaluated. All children with hernia repair during that period have been evaluated $(n=52)$. We included only children who underwent an isolated inguinal hernia repair and who had no concomitant diseases $(n=42)$. Patients with congenital organ disorders like cardiovascular disease that could affect mean arterial pressure were not included into the study.

\section{Definition of target size}

In order to define a critical margin of mean arterial blood pressure we refer to a study by Rhondali et al. who conducted a retrospective analysis to compare the data of cerebral blood flow (CBF) and brain oxygenation in 180 children younger than 6 months. The authors stated that the mean arterial pressure is a good proxy of cerebral perfusion as they found that the CBF decreased proportionally with cerebral perfusion pressure. They regarded a mean arterial pressure beyond $35 \mathrm{mmHg}$ during anesthesia to be safe and sufficient [8]. Therefore, we defined the incidence of a mean arterial pressure below $35 \mathrm{mmHg}$ as the primary target. Secondary target sizes were the extent of fall of mean arterial pressure below the limit of $35 \mathrm{mmHg}$ as well as the cumulative time per patient below that limit.

\section{Data handling}

Vital parameters were automatically recorded by use of a patient data management system (IntelliSpace Critical Care and Anesthesia (ICCA); Version H.02.01.001, Philips ${ }^{\ominus}$. Evaluation of the data was carried out manually. Statistical analysis was performed by GraphPadPrism ${ }^{\circ}$ 5.02. The Shapiro-Wilk's test for normality was used to check for normal distribution. Normal distributed groups were compared with the 2-sample 2-sided t-test. Otherwise the Mann-Whitney-U Test was used.

\section{Results}

In this study a retrospective analysis was performed in very low birthweight neonates (birthweight 1000 - $1500 \mathrm{~g}$ ) receiving inguinal hernia repair. Two groups were compared: neonates with awake caudal anesthesia without sedation (CA) and neonates with a caudal block in combination with general anesthesia $(\mathrm{GA}+\mathrm{CA})$. At our institution we left treating preterm neonates for inguinal hernia repair without caudal block over a decade, since we rated the well-known advantages of regional anesthesia as so convincing $[9,10]$. Therefore, a third study arm (general anesthesia alone) was not created. Table 1 shows that baseline characteristics are well balanced between both groups of very low birthweight infants. Patients who received CA had a lower body weight at the time of the surgical procedure. However, the difference is tiny and we therefore did not adjust for any baseline characteristic in our analysis. Median post menstrual age at birth was 31.6 weeks $(\mathrm{GA}+\mathrm{CA})$ vs $30.1(\mathrm{CA})$. Post menstrual age at the time of operation was 39.8 weeks $(\mathrm{GA}+\mathrm{CA})$ vs $37.8(\mathrm{CA})$. 
Table 1 Baseline characteristics of very low birthweight infants receiving open inguinal hernia repair. Sixteen patients (11 boys, 5 girls) received a caudal anesthesia as a stand-alone method, 26 patients (22 boys, 4 girls) a combination of a general anesthesia with a caudal anesthesia. The baseline characteristics are well balanced between both groups (Mann-Whitney-U test)

\begin{tabular}{|c|c|c|c|c|c|c|c|}
\hline & \multicolumn{3}{|c|}{$\mathrm{GA}+\mathrm{CA}(n=26)$} & \multicolumn{3}{|c|}{ CA $(n=16)$} & \multirow[b]{2}{*}{$P$} \\
\hline & Median & 25-75\% percentile & Min - Max & Median & $25-75 \%$ percentile & Min - Max & \\
\hline birthweight [g] & 1390 & $778-1850$ & $560-2450$ & 1220 & 869-1593 & $570-2150$ & 0.32 \\
\hline PMA at birth [weeks] & 31.57 & 29.68-34.07 & $25.57-38.86$ & 30.07 & $27.00-32.72$ & $24.29-34.29$ & 0.11 \\
\hline Weight at OR [g] & 2990 & $2375-3400$ & $2000-3600$ & 2400 & $2149-3050$ & $2000-3600$ & 0.05 \\
\hline PMA at OR [weeks] & 39.79 & $36.86-41.61$ & $35.14-48.29$ & 37.79 & $36.40-39.71$ & $35.43-43.71$ & 0.11 \\
\hline Duration of surgery [min] & 25.5 & $19.5-49.0$ & $14.0-66.0$ & 29.5 & $19.75-40.0$ & $8.0-66.0$ & 0.9 \\
\hline
\end{tabular}

PMA Post menstrual age, OR Operation

Sixteen patients (11 boys, 5 girls) received a CA, while 26 patients ( 22 boys, 4 girls) received a GA + CA.

Caudal anesthesia was performed in patients in a lateral decubitus position with left side down. The puncture site was preoperatively anesthetized with EMLA ${ }^{\circ}$. After implementation of an intravenous infusion and monitoring of vital parameters the patient was placed in a lateral decubitus position with left side down. An Epican ${ }^{\circ}$ Paed25G was guided by a SonoSite ${ }^{\bullet}$ M-Turbo with linear probe (5-13 $\mathrm{MHz}$ ) in long axis in-plane-technique and the needle tip advanced under direct visualization. After negative aspiration, local anesthetic (ropivacaine $0.375 \% ; 1 \mathrm{ml} / \mathrm{kg}$ ) was applied and its spread assessed by ultra sound (Fig. 1).

The patients received no further medication until the end of anesthesia.

General anesthesia was either induced by mask ventilation with sevoflurane or by intravenous injection of 2-4 $\mathrm{mg} / \mathrm{kg}$ propofol. In 12 patients the trachea was intubated, and in 14 patients the airway was secured by use of a laryngeal mask (Ambu ${ }^{\circ}$ AuraOnce $\left.{ }^{\mathrm{nm}}\right)$. In order to facilitate intubation of the trachea the muscle relaxant vecuronium $(0.1 \mathrm{mg} / \mathrm{kg})$ was applied. General anesthesia was maintained with sevoflurane $(0.5-2.9 \mathrm{Vol} \%$ corresponding to 0.3-1 MAC), 13 patients received additionally remifentanil (0.1-0.3 $\mu \mathrm{g} / \mathrm{kg} / \mathrm{min}$ ) (Fig. 2, Table 2) After induction of general anesthesia, a caudal block was applied as described above. In contrast to patients with $\mathrm{CA}$, the local anesthetic was used in a concentration of $0.2 \%(1 \mathrm{ml} / \mathrm{kg})$. This anesthetic practice followed in-house standard operating procedures and was not changed within the study period. As a result, all caudal blocks were successful and there were no complications or side effects registered.

Patients in both groups received an intravenous isotonic full electrolyte solution including $1 \%$ glucose with an infusion rate of $10 \mathrm{ml} / \mathrm{kg} / \mathrm{h}$. Basic vital parameters like blood pressure, heart rate, oxygen saturation and body temperature were continuously monitored during the operation and automatically recorded.

In accordance with the American Heart Association (AHA) recommendations for blood pressure measurement in children, cuff bladder width was at least $40 \%$ of the arm circumference halfway between the olecranon and acromion. The cuff covered at least $80 \%$ of the arm circumference.

In Fig. 3 we plotted the individual courses of the patients' mean arterial blood pressure. According to Rhondali et al. we defined a mean arterial pressure above 35 $\mathrm{mmHg}$ to be safe in this population [8]. The mean recording period was $47.4 \pm 24.3 \mathrm{~min}$. As demonstrated in Fig. 3a, approximately half of the mean blood pressure values were below the defined critical threshold of 35 $\mathrm{mmHg}$ in the GA + CA group, whereas this was the case in only $3 \%$ in the CA group (Fig. 3b). $57.7 \%$ of the patients in the GA + CA group underran the critical margin of $35 \mathrm{mmHg}$ compared to $18.8 \%$ in the CA group.

In the following step we quantified these episodes with a critical mean arterial blood pressure. As depicted in Fig. 4, both severity of MAP (Fig. $4 \mathrm{a})(4.7 \pm 2.7 \mathrm{mmHg}$ vs $1.9 \pm$ $1.6 \mathrm{mmHg}$ ) and mean cumulative time per patient of MAP below $35 \mathrm{mmHg}$ (Fig. 4b) $(25.6 \pm 26.0 \mathrm{~min}$ vs $0.9 \pm$ $2.3 \mathrm{~min}$ ) were significantly higher in the GA + CA group.

Intraoperative interventions to stabilize blood pressure are summarized in Table 3. The application of full electrolyte solution (Jonosteril ${ }^{\circ}$ ) or a vasopressor (Akrinor ${ }^{\circ}$; cafedrine/theoadrenaline) was at the discretion of the anesthesiologist. In the GA + CA group 15 out of 26 patients $(57.7 \%)$ received a volume bolus in contrast to 3 out of 16 patients (18.8\%) in the CA group. The median cumulative amount of bolus volume applied to patients in this group was significantly lower $(10 \pm 4.1 \mathrm{ml}$ vs. $27 \pm 14.8 \mathrm{ml} ; \mathrm{p}=0.0015)$. In accordance with this, vasopressor application was less frequent in the caudal anesthesia group (0\% versus $19 \%)$.

\section{Discussion}

In this retrospective study we evaluated the course of intraoperative blood pressure in very low birthweight infants who received either caudal anesthesia, as a stand alone method, or a combination of general anesthesia, and caudal anesthesia, both for inguinal hernia repair. Anesthesia in both groups was performed by senior anesthetists with more than 5 years experience in the 


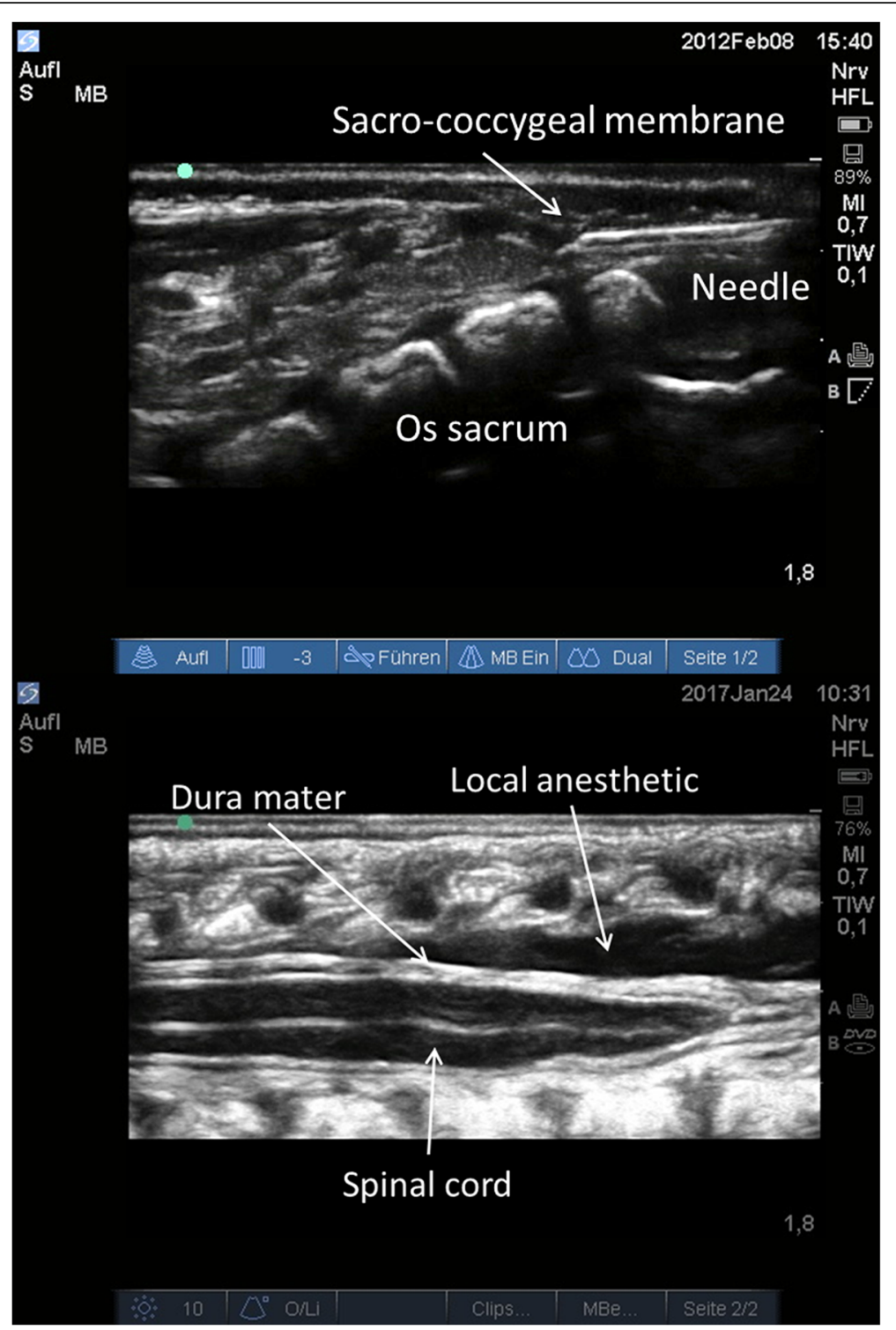

Fig. 1 Ultrasound images of the implementation of caudal anaesthesia in very low birth weight infants scheduled for open inguinal hernia repair. Caudal anaesthesia was implemented in infants placed in a lateral decubitus position with the left side down. Correct needle placement and distribution of the local anaesthetic was observed in all patients as visible on the ultrasound image and led to a surgically sufficient analgesia. Both pictures show a long axis view of the spinal canal. a Puncture with an Epican Paed25G was performed in an in-plane technique by means of a SonoSite ${ }^{\oplus} \mathrm{M}$-Turbo with linear probe $(5-13 \mathrm{MHz})$. $\mathbf{b}$ The ultrasound picture in in-plane technique demonstrates the spread of the local anaesthetic (ropivacaine $0.375 \% ; 1 \mathrm{ml} / \mathrm{kg}$ )

care of very low birthweight infants. As reported in the results section we did not investigate the effects of general anesthesia as a stand alone method, although general anesthesia may still be used in many institutions for this type of surgery. In our opinion, the two study arms are justifiable since the aim of our study was to find out potential advantages of caudal anesthesia as a standalone method in preterm neonates. Furthermore, we know from literature that arterial blood pressure is not altered by caudal anesthesia in children receiving general anesthesia (Larousse et al. 2002), a finding that was supported by a prospective study in neonates by Deng et al. in 2008 [6, 7].

The most striking result is that the mean blood pressure was significantly lower in the GA + CA group although there were more pharmacological interventions like application of vasopressors or volume boluses. It is of even more importance that approximately $47 \%$ of the measured mean arterial blood pressure values in that group were below a critical margin of $35 \mathrm{mmHg}$, in contrast to only $3 \%$ in the CA group and that the cumulative time below $35 \mathrm{mmHg}$ per patient was significantly 


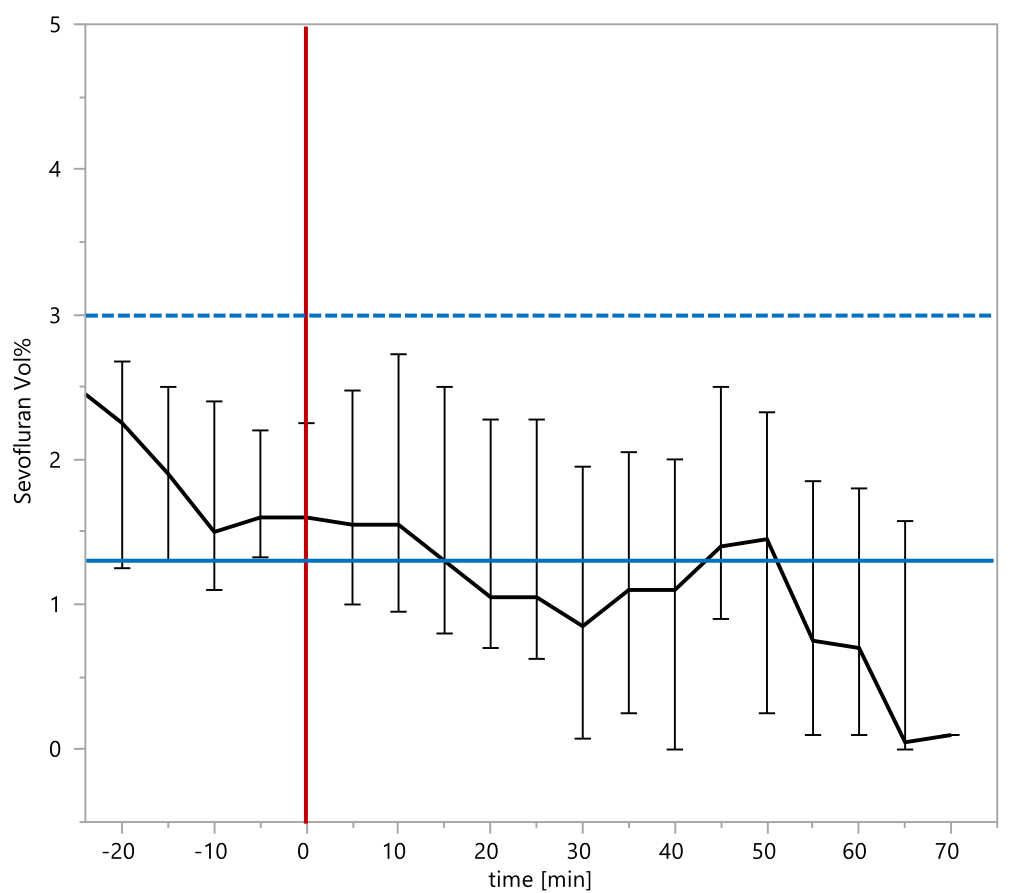

Fig. 2 Time course of the median sevoflurane concentration (median \pm interquartile range) calculated from patients in the group of combined general- and caudal anesthesia. The time point " $0 \mathrm{~min}^{\prime}$ indicates the start of the surgical procedure and is marked by the vertical red line. The dashed blue line indicates a sevoflurane concentration of $3.0 \mathrm{vol} \%$ corresponding to $1 \mathrm{MAC}$. The blue line represents the median sevoflurane concentration of 1.3 vol\% during the maintenance phase of general anesthesia

longer. A safe lower limit of blood pressure in infants is still a matter of debate. The incidence of hypotension in preterm neonates seems to be inversely related to gestational age and birth weight [11]. General anesthesia can contribute to hypotension, and thereby cause low cerebral perfusion $[1,8]$. This seems to be less critical in preterm neonates who do not undergo surgical intervention since Alderliesten et al. described that a mean arterial blood pressure less than gestational age in weeks was not associated with lower neurodevelopmental outcome scores [11]. On the other hand McCann et al. reported on 6 infants who underwent elective surgery and developed postoperative encephalopathy, which had features most consistent with intraoperative cerebral hypoperfusion [3]. However, in a retrospective analysis in children younger than 6 months conducted by Rhondali et al., the authors compared data of two studies investigating the impact of sevoflurane anesthesia on cerebral blood flow by transcranial
Doppler [12] and on brain oxygenation by NIRS [13]. The authors reported that in healthy infants scheduled for short procedures, the mean arterial pressure is a good surrogate parameter of cerebral perfusion. Even more Rhondali et al. stated that maintaining the mean arterial pressure above $35 \mathrm{mmHg}$ during anesthesia is safe and sufficient [8], and we adopted this value as a lower threshold. It is important to mention that general anesthetics were administered at low concentrations, e.g. sevoflurane was dosed by approximately 0.5 MAC (median $1.3 \mathrm{vol} \%$ ) during the maintenance phase of general anesthesia which is far less compared to sevoflurane concentrations reported in other studies (Fig. 2) [13, 14]. Even for sedation the application of either $8 \mathrm{vol} \%$ sevoflurane or up to $4 \mathrm{mg} /$ $\mathrm{kg}$ propofol during the initiation of a caudal block were reported $[15,16]$. Thus it can be estimated that with a less cautious use of general anesthetics even more episodes of low mean arterial pressure can be expected.

Table 2 The table summarizes the doses and ranges of anesthetic agents used in the group of combined general- and caudal anesthesia

\begin{tabular}{llll}
\hline Anesthetic agent & i.v. Induction $(\mathrm{n})$ & Mask Induction $(\mathrm{n})$ & maintenance of anesthesia $(\mathrm{n})$ \\
\hline Propofol $[\mathrm{mg} / \mathrm{kg}]$ & $2-4(11)$ & - & - \\
Sevofluran $[\mathrm{vol} \%]$ & - & $0.6-7.3(15)$ & $0.5-2.9[$ mean 1.3] (26) \\
Remifentanil $[\mathrm{kg} / \mathrm{kg} / \mathrm{min}]$ & - & - & $0.1-0.3(13)$ \\
Vecuronium $[\mathrm{mg} / \mathrm{kg}]$ & $0.1(4)$ & - & - \\
\hline
\end{tabular}


A

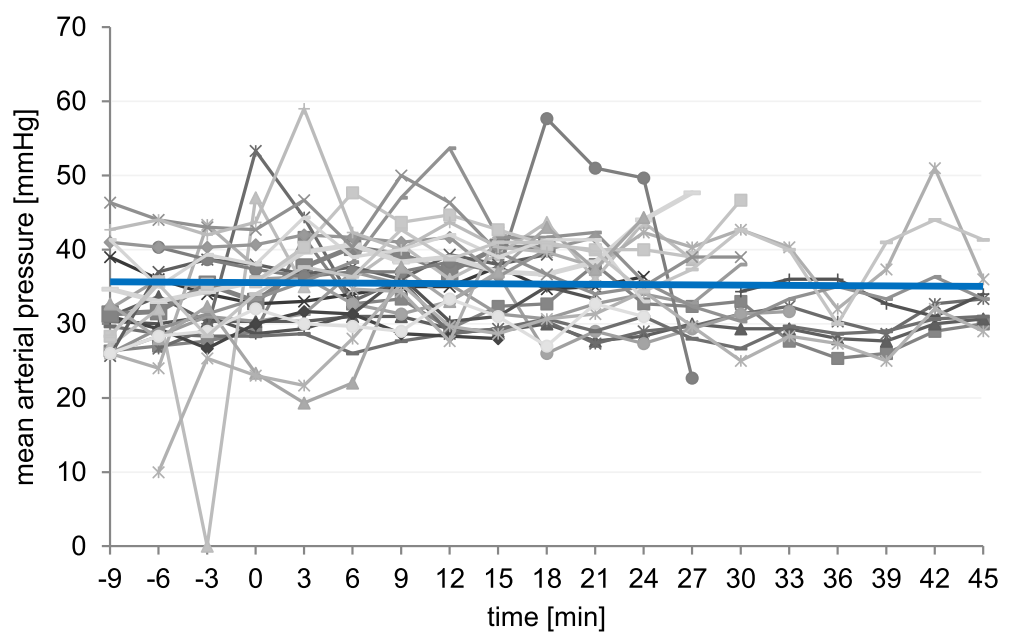

B

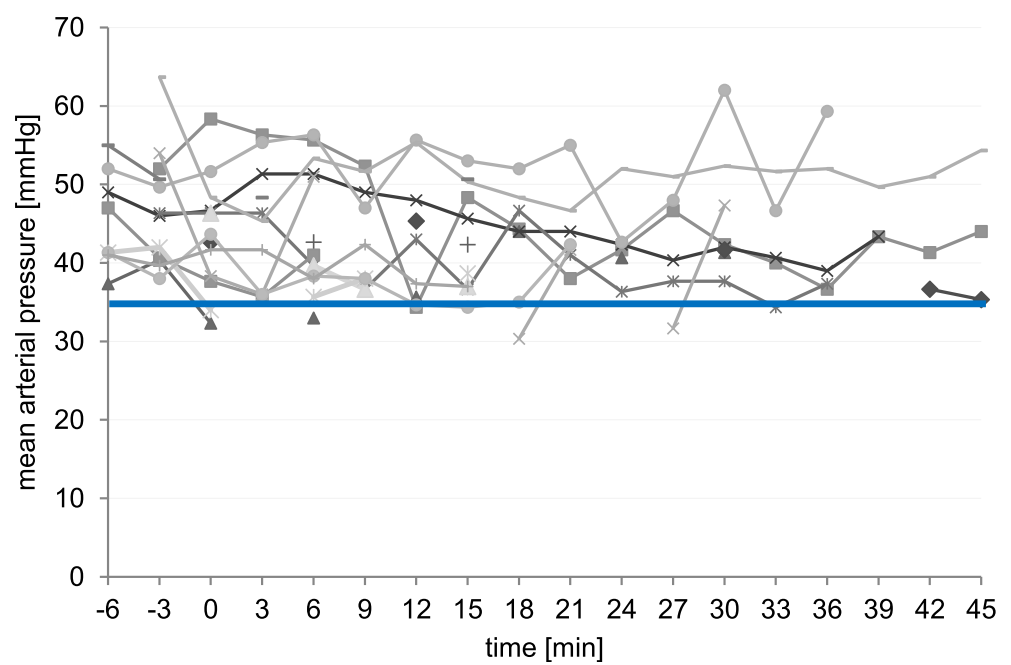

Fig. 3 The graph depicts the individual courses of mean arterial blood pressure in very low birth weight infants during open inguinal hernia repair. Each character represents a single patient. The surgical procedure started at the time point 0 min. For easier interpretation of the data a blue line was drawn at $35 \mathrm{mmHg}$, since this value marked the threshold that was defined to be safe according to Rhondali et al. [8] a The graph visualizes that in the group of combined general- and caudal anesthesia approximately half of the mean blood pressure values measured during inguinal hernia repair were below the critical threshold of $35 \mathrm{mmHg}$. $\mathbf{b}$ In contrast to the patients in the group of combined general- and caudal anesthesia only $3 \%$ of all mean blood pressure values measured in the caudal anesthesia group underran the critical margin of $35 \mathrm{mmHg}$

In very low birthweight infants we use caudal anesthesia rather than spinal anesthesia since the success rates are significantly higher $[14,15,17,18]$. The quality of caudal blockade provided adequate surgical conditions in all cases although a lack of sufficient motor blockage was often considered to be disadvantageous $[17,19]$. For this ropivacain $0,375 \%$ was used in the CA group without any side effects. In contrast to spinal anesthesia, the implementation of a caudal block is technically less difficult and became even more straightforward by use of ultrasound control since puncture and correct spread of the local anesthetic can be tracked visually, especially when the needle is visualized in long axis in a sagittal plane [20,21]. Another advantage is the chance to identify anatomical anomalies like for example a terminal myelocystocele, a myelomeningocele or a tight filum terminale syndrome [22] before puncture.

The retrospective analysis suffers from some limitations like the limited number of patients being anesthetized by only two anesthetists or that an association of intraoperative hypotension to general anesthetics like remifentanil or sevoflurane cannot be derived. Likewise no sequelae could be recorded in this retrospective study. However, the anesthetists each had at least 5 years 


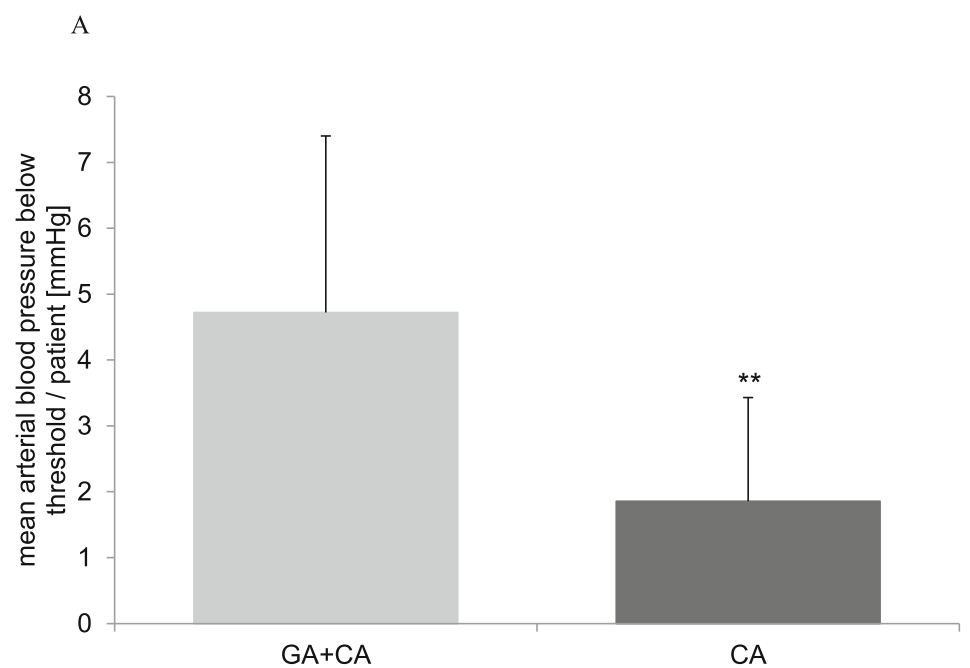

B

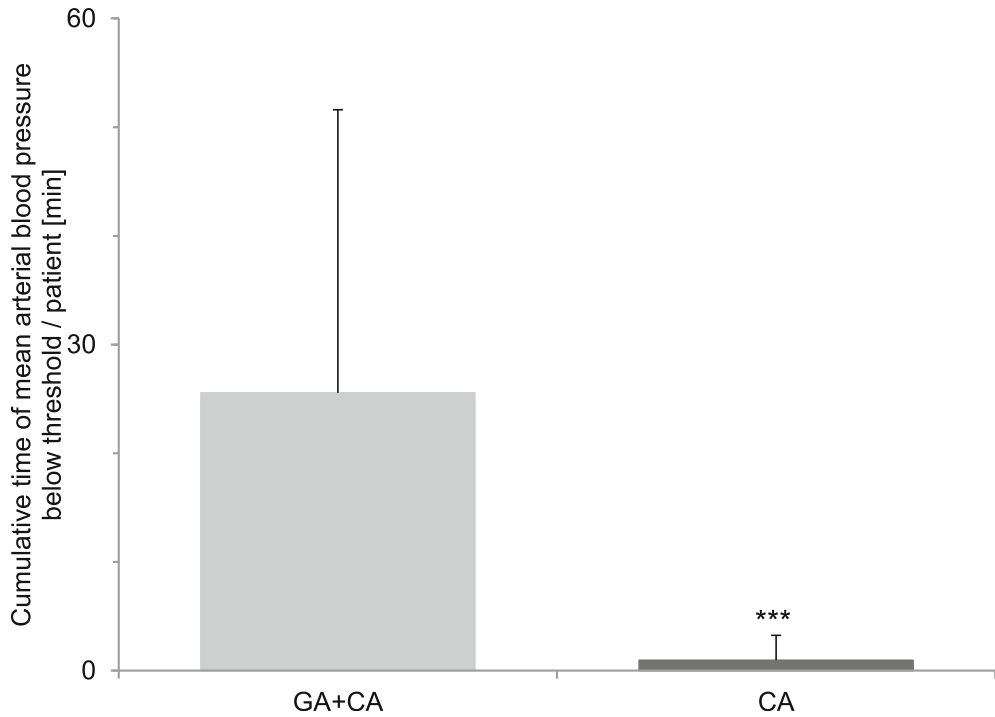

Fig. 4 Evaluation of potentially critical episodes (mean arterial blood pressure values below $35 \mathrm{mmHg}$ ) in both groups of very low birth weight infants receiving open inguinal hernia repair. a The figure demonstrates that the extent to which the critical limit of $35 \mathrm{mmHg}$ was underran is significantly greater in the group of combined general- and caudal anesthesia $(G A+C A)(* * ; P<0.01)$. $\mathbf{b}$ Analysis of the mean cumulative time per patient with a mean arterial pressure value below $35 \mathrm{mmHg}$. Patients in the group of combined general- and caudal anesthesia (GA + CA) spent significantly longer time with mean arterial pressure below $35 \mathrm{mmHg}$ compared to patients in the caudal anesthesia (CA) group (***; $P<0.001)$

Table 3 depicts intraoperative interventions to raise blood pressure in very low birthweight children receiving open inguinal hernia repair. Full electrolyte solution boli (Jonosteri ${ }^{\oplus}$ ) or vasopressor boli (Akrinor ${ }^{\oplus}$; cafedrine/theoadrenaline) were administered at the discretion of the anaesthesiologist (Mann-Whitney- $U$ test)

\begin{tabular}{|c|c|c|c|c|}
\hline & & $G A+C A(n=26)$ & $\mathrm{CA}(n=16)$ & $P$ \\
\hline \multirow[t]{2}{*}{ Fluid bolus } & Patients n [\%] & $15[57.7]$ & $3[18.8]$ & 0.0046 \\
\hline & Average fluid bolus [ml/patient] [mean] & $27 \pm 14.8$ & $10 \pm 4.1$ & 0.0015 \\
\hline \multirow[t]{2}{*}{ Cafedrine / theoadrenaline } & Patients n [\%] & $5[19.2]$ & $0[0]$ & $<0.001$ \\
\hline & Average vasopressor bolus [ml/patient] [mean] & $0.15 \pm 0.06$ & 0 & $<0.001$ \\
\hline
\end{tabular}


of experience in pediatric anesthesia and were aware of keeping the mean arterial pressure above $35 \mathrm{mmHg}$ which was difficult in the group of combined generaland caudal anesthesia in spite of the use of volume boluses and vasopressors and resulted in significantly more episodes of critically low mean arterial blood pressure.

\section{Conclusion}

In summary this preliminary study provides support for the use of caudal block as a stand alone method for the care of very low birthweight infants as it shows advantages in preventing critical blood pressure drops compared to a combination of caudal block with general anesthesia.

\begin{abstract}
Abbreviations
AHA: American heart association; CA: Awake caudal anesthesia without sedation; CBF: Cerebral blood flow; g: Gram; G: Gauge; G1\%: Glucose 1\%; GA + CA: General anesthesia with caudal block; ICCA: Intellispace Critical Care and Anesthesia information system; MAC: Minimum alveolar concentration; MAP: Mean arterial blood pressure; MHz: Megaherz; ml: Milliliter; mmHg: Millimeter mercury column; NIRS: Near-infrared spectroscopy; OR: Operation; PMA: Post menstrual age; vs: Versus
\end{abstract}

\section{Acknowledgements}

Not applicable.

\section{Authors' contributions}

FF helped with the planning of the study, the data collection, the compilation of statistics as well as the constitution of the manuscript. MW contributed to the data collection, evaluation of patient files and compilation of statistics. CG helped with the planning of the study, the compilation of statistics and the constitution of the manuscript. The authors read and approved the final manuscript.

\section{Funding}

Open access funding provided by Projekt DEAL.

\section{Availability of data and materials}

The datasets used and/or analysed during the current study are available from the corresponding author on reasonable request.

\section{Ethics approval and consent to participate}

was provided by the University of Tuebingen Ethical Committee, Chairman Prof. Luft, on 05/29/2018 with the project number 403/2018BO2. The Ethics Committee's approval was conditional on the written consent of the parents or legal guardians of all patients.

\section{Consent for publication}

Not applicable.

\section{Competing interests}

The authors declare that they have no competing interests.

\section{Author details}

${ }^{1}$ Departmnt of Anesthesiology and Intensive Care Medicine, University Hospital Tuebingen, Tübingen, Germany. ${ }^{2}$ Clinic for Anesthesiology, Intensive, Emergency- and Pain-Therapy, Ludwigsburg, Germany.

Received: 4 November 2019 Accepted: 13 July 2020

Published online: 20 July 2020

\section{References}

1. Michelet D, Arslan O, Hilly J, Mangalsuren N, Brasher C, Grace R, et al. Intraoperative changes in blood pressure associated with cerebral desaturation in infants. Paediatr Anaesth. 2015;25(7):681-8.

2. Williams M, Lee JK. Intraoperative blood pressure and cerebral perfusion: strategies to clarify hemodynamic goals. Paediatr Anaesth. 2014;24(7):657-67.
3. McCann ME, Schouten AN, Dobija N, Munoz C, Stephenson L, Poussaint TY, et al. Infantile postoperative encephalopathy: perioperative factors as a cause for concern. Pediatrics. 2014;133(3):e751-7.

4. Marhofer $P$, Keplinger M, Klug W, Metzelder ML. Awake caudals and epidurals should be used more frequently in neonates and infants. Paediatr Anaesth. 2015;25(1):93-9.

5. Ing C, Sun LS, Friend AF, Kim M, Berman MF, Paganelli W, et al. Differences in intraoperative hemodynamics between spinal and general anesthesia in infants undergoing pyloromyotomy. Paediatr Anaesth. 2017;27(7):733-41.

6. Larousse E, Asehnoune K, Dartayet B, Albaladejo P, Dubousset AM, Gauthier $F$, et al. The hemodynamic effects of pediatric caudal anesthesia assessed by esophageal Doppler. Anesth Analg. 2002;94(5):1165-8 table of contents.

7. Deng $M$, Wang $X$, Wang $L$, Zheng $S$. The hemodynamic effects of newborn caudal anesthesia assessed by transthoracic echocardiography: a randomized, double-blind, controlled study. Paediatr Anaesth. 2008;18(11):1075-81.

8. Rhondali O, Andre C, Pouyau A, Mahr A, Juhel S, De Queiroz M, et al. Sevoflurane anesthesia and brain perfusion. Paediatr Anaesth. 2015;25(2):180-5.

9. Sanders RD, Ma D, Brooks P, Maze M. Balancing paediatric anaesthesia: preclinical insights into analgesia, hypnosis, neuroprotection, and neurotoxicity. Br J Anaesth. 2008;101(5):597-609.

10. Lonnqvist PA. Regional anaesthesia and analgesia in the neonate. Best Pract Res Clin Anaesthesiol. 2010;24(3):309-21.

11. Alderliesten T, Lemmers PM, van Haastert IC, de Vries LS, Bonestroo HJ, Baerts W, et al. Hypotension in preterm neonates: low blood pressure alone does not affect neurodevelopmental outcome. J Pediatr. 2014;164(5):986-91.

12. Rhondali O, Mahr A, Simonin-Lansiaux S, De Queiroz M, Rhzioual-Berrada K, Combet $\mathrm{S}$, et al. Impact of sevoflurane anesthesia on cerebral blood flow in children younger than 2 years. Paediatr Anaesth. 2013;23(10):946-51.

13. Rhondali O, Juhel S, Mathews S, Cellier Q, Desgranges FP, Mahr A, et al. Impact of sevoflurane anesthesia on brain oxygenation in children younger than 2 years. Paediatr Anaesth. 2014;24(7):734-40.

14. Davidson AJ, Disma N, de Graaff JC, Withington DE, Dorris L, Bell G, et al. Neurodevelopmental outcome at 2 years of age after general anaesthesia and awake-regional anaesthesia in infancy (GAS): an international multicentre, randomised controlled trial. Lancet (London, England). 2016; 387(10015):239-50.

15. Brenner L, Kettner SC, Marhofer $P$, Latzke D, Willschke $H$, Kimberger $O$, et al. Caudal anaesthesia under sedation: a prospective analysis of 512 infants and children. Br J Anaesth. 2010;104(6):751-5.

16. Brenner L, Marhofer P, Kettner SC, Willschke H, Machata AM, Al-Zoraigi U, et al. Ultrasound assessment of cranial spread during caudal blockade in children: the effect of different volumes of local anaesthetics. Br J Anaesth. 2011;107(2):229-35.

17. Dalens B, Hasnaoui A. Caudal anesthesia in pediatric surgery: success rate and adverse effects in 750 consecutive patients. Anesth Analg. 1989;68(2):83-9.

18. Suresh S, Long J, Birmingham PK, De Oliveira GS Jr. Are caudal blocks for pain control safe in children? An analysis of 18,650 caudal blocks from the pediatric regional anesthesia network (PRAN) database. Anesth Analg. 2015; 120(1):151-6.

19. Hoelzle M, Weiss M, Dillier C, Gerber A. Comparison of awake spinal with awake caudal anesthesia in preterm and ex-preterm infants for herniotomy. Paediatr Anaesth. 2010;20(7):620-4.

20. Wang LZ, Hu XX, Zhang YF, Chang XY. A randomized comparison of caudal block by sacral hiatus injection under ultrasound guidance with traditional sacral canal injection in children. Paediatr Anaesth. 2013;23(5):395-400.

21. Ahiskalioglu A, Yayik AM, Ahiskalioglu EO, Ekinci M, Golboyu BE, Celik EC, et al. Ultrasound-guided versus conventional injection for caudal block in children: a prospective randomized clinical study. J Clin Anesth. 2018;44:91-6.

22. Unsinn KM, Geley T, Freund MC, Gassner I. US of the spinal cord in newborns: spectrum of normal findings, variants, congenital anomalies, and acquired diseases. Radiographics. 2000;20(4):923-38.

\section{Publisher's Note}

Springer Nature remains neutral with regard to jurisdictional claims in published maps and institutional affiliations. 